\title{
Rates and Predictors of Uncontrolled Hypertension Among Hypertensive Homeless Adults Using New York City Shelter-Based Clinics
}

\author{
Ramin Asgary, MD, $M P H^{1,2}$ \\ Blanca Sckell, MD, MPH \\ Analena Alcabes, $B^{2}$ \\ Ramesh Naderi, $M D^{1}$ \\ Antoinette Schoenthaler, EdD, $M A^{1}$ \\ Gbenga Ogedegbe, $M D, M P H^{1}$ \\ 'Departments of Population Health and \\ Medicine, New York University School of \\ Medicine, New York, New York \\ ${ }^{2}$ Community Medicine Program, NYU \\ Lutheran, New York, New York
}

\begin{abstract}
PURPOSE We undertook a study to determine the rates, predictors, and barriers to blood pressure control among homeless and nonhomeless hypertensive adult patients from 10 New York City shelter-based clinics.

METHODS The study was a retrospective chart review of blood pressure measurements, sociodemographic characteristics, and factors associated with homelessness and hypertension extracted from the medical records of a random sample of hypertensive patients $(\mathrm{N}=210)$ in 2014 .
\end{abstract}

RESULTS Most patients were African American or Hispanic; $24.8 \%$ were female, and $84.3 \%$ were homeless for a mean duration of 3.07 years (SD $=5.04$ years). Homeless adult patients were younger, had less insurance, and were more likely to be a current smoker and alcohol abuser. Of the 210 hypertensive patients, $40.1 \%$ of homeless and $33.3 \%$ of nonhomeless patients had uncontrolled blood pressure $(P=.29)$ when compared with US rates for hypertensive adults, which range between $19.6 \%$ and $24.8 \%$, respectively; $15.8 \%$ of homeless patients had stage 2 hypertension $(P=.27)$. Homeless hypertensive patients with diabetes or multiple chronic diseases had better blood pressure control $(P<.01)$. In logistic regression, lack of insurance was associated with inadequate blood pressure control $(P<.05)$.

CONCLUSIONS The high rate of uncontrolled hypertension among hypertensive homeless adults is alarming. We propose comprehensive approaches to improve social support, access to medical insurance, and medication adherence, the lack of which complicate blood pressure control, targeted health education, and life style modifications using mobile health strategies for this mobile population.

Ann Fam Med 2016;14:41-46. doi: 10.1370/afm.1882.

\section{INTRODUCTION}

nnually millions of Americans experience homelessness, and approx-
imately 630,000 spend each night in the shelter system. ${ }^{1,2}$ Most
homeless adults were born during the latter part of the baby boom era and are now entering their 50s, placing them at a higher risk of developing hypertension. ${ }^{3,4}$ Hypertension is one of the most common conditions among homeless adults ${ }^{5-10}$; however, data on blood pressure control in the homeless is very limited. ${ }^{6,11}$ The homeless are also more likely to be smokers and have a history of cocaine abuse. , $, 8,11,12$ They lack access to primary care and suffer from mental illness or substance abuse, ${ }^{4,13}$ experience discrimination in the health system, and face barriers to therapeutic lifestyle changes ${ }^{7}$ factors that likely complicate their chronic disease management.

There are effective and proven strategies to control blood pressure in the general population, including self-management behaviors and counseling to support lifestyle changes. ${ }^{14-18}$ These strategies are rarely evaluated among the homeless or disseminated to health facilities where the homeless seek care, partly because data regarding the rates and predictors of poor blood pressure control among the homeless are lacking. This study aims to assess the rates and predictors of uncontrolled blood pressure
Ramin Asgary, MD, MPH

Departments of Population Health and Medicine

New York University School of Medicine Translational Research Building, Room 639 227 E 30th St

New York, NY 10016

ramin.asgary@caa.columbia.edu

\footnotetext{
aims to assess the rates and predictors of uncontrolled blood pressure
} 
among hypertensive homeless adults and a nonhomeless, low-socioeconomic adult population who use New York City's shelter-based clinics. The results will guide interventions aimed at improving control among this vulnerable population.

\section{METHODS}

\section{Study Design and Setting}

The Community Medicine Program (CMP) of the NYU Lutheran Family Health Centers provides medical services to the homeless population of New York City at various shelters and shelter-based clinics. We conducted a retrospective chart review to determine and compare the rates of uncontrolled hypertension among homeless and nonhomeless hypertensive adults who used 10 shelter-based clinics in New York City and to determine factors associated with uncontrolled hypertension. The Institutional Review Board at NYU Lutheran Family Health Centers approved this study.

We collected a computer-generated random sample of patients with a diagnosis of hypertension from 10 shelter-based clinics in 2013 and early 2014 in 3-month intervals to account for potential seasonal effects. Electronic medical records were then reviewed to document systolic and diastolic blood pressure readings in the latest recorded visit. Blood pressure was evaluated based on the JNC-7 recommendations..$^{19}$ Inclusion criteria included hypertensive homeless and nonhomeless patients receiving care at CMP shelter-based clinics during 2013 to $2014 .{ }^{19}$ We collected the following sociodemographic characteristics and clinical and nonclinical data: age, race, and sex $x_{i}$ housing status and years of homelessness; body mass index ${ }_{i}$ health insurance status; personal history of chronic diseases, including diabetes, renal insufficiency, hypercholesterolemia, asthma or chronic obstructive pulmonary disease, and coronary artery disease; tobacco, alcohol and substance abuse $_{i}$ and history of mental illness, including mood disorders, psychosis, and neurosis or anxiety disorders. One trained research team member reviewed all medical records and extracted data. A second research team member double-checked the accuracy of the data collection. We defined homeless status when a patient indicated that he/she lives in a shelter or on the street. Years of homelessness were recorded when indicated in the medical records. Current history of chronic illness, mental illness, alcohol abuse, and smoking and substance abuse were defined as reported by patients and indicated by the physician in the records.

\section{Study Outcomes and Statistical Analyses}

The primary outcome was the rate of uncontrolled hypertension measured as a dichotomous/categori- cal variable (levels of blood pressure as either stage 1 , uncontrolled, $140 / 90$ to $160 / 100 \mathrm{~mm} \mathrm{Hg}_{i}$ or stage 2, very uncontrolled, 160/100 mm Hg or higher). Secondary outcomes included factors associated with homelessness and hypertension, including alcohol, smoking, substance abuse, and history of mental illness and chronic disease. The main independent variable was housing status, which was dichotomous; the duration of homelessness was evaluated as a continuous variable. All other independent variables were dichotomous/categorical except age, number of mental illnesses and chronic diseases, and number of cigarettes smoked daily.

We calculated and reported the numbers of events and proportions and compared the rates of primary and secondary outcomes. Descriptive statistics, univariate and bivariate analysis using $\chi^{2}$ and the Student $t$ test, as well as multivariable logistic regression with adjusted odds ratios and $95 \%$ confidence intervals, were performed where indicated. We determined statistical significance for differences in rates between groups using the two-sided $\chi^{2}$ or $t$ test. We used logistic regression analysis to assess the presence and degree of association between independent variables with the rate of uncontrolled hypertension and to control for potential confounders. Variables were included in the models when bivariate analysis showed significance and when clinically sensible and plausible. We looked at the correlation of predictors of blood pressure control between the nonhomeless and homeless and within the homeless population. SPSS 21.0 (International Business Machines Corp) was used for data analysis. In the absence of prior studies, and considering our arbitrary threshold to consider a targeted program, we hypothesized that the prevalence of uncontrolled hypertension among our patient population needed to be at least $15 \%$. We set $\alpha$ at .05 with a power of 0.8 and calculated the sample size of $196 .^{20}$

\section{RESULTS}

The total number of participants that met our inclusionexclusion criteria was 210 . Their average age was 55.74 years, $84.3 \%$ were homeless. Most were African American and Hispanic ${ }_{i} 24.8 \%$ were female. Of the homeless and nonhomeless patients, $40.1 \%$ and $33.3 \%$ had uncontrolled blood pressure levels, respectively $(P=.29$; odds ratio $[\mathrm{OR}]=1.34 ; 95 \% \mathrm{CI}, 0.61-2.93)$. The rates of stage 2 hypertension $(\geq 160 / 100 \mathrm{~mm} \mathrm{Hg})$ was $15.8 \%$ in the homeless and $0.03 \%$ in the nonhomeless patients $(P=.27)$. The homeless were younger ( 55.10 vs 59.15 years $;=.04)$, more likely to be uninsured $(\mathrm{OR}=1.22$; $95 \% \mathrm{CI}, 1.14-1.31 ; P=.01)$, less likely to have hypercholesterolemia $(\mathrm{OR}=0.32 ; 95 \% \mathrm{CI}, 0.17-0.6 ; P=.001)$ or coronary artery disease $(\mathrm{OR}=0.50 ; 95 \% \mathrm{CI}, 0.26$ - 
0.95; $P=.03)$, and more likely to be a current smoker $(\mathrm{OR}=2.36 ; 95 \% \mathrm{CI}, 1.15-4.85 ; \mathrm{P}=0.01)$ and abuse alcohol $(\mathrm{OR}=5.39 ; 95 \% \mathrm{CI}, 1.39-8.0 ; \mathrm{P}=.04)$. There was no significant difference between the homeless and nonhomeless patients in regard to prevalence of mental illness $(\mathrm{OR}=0.7 ; 95 \% \mathrm{CI}, 0.31-1.58 ; \mathrm{P}=.43)$. Table 1 displays the demographic characteristics and clinical indicators among all study patients.

The average duration of homelessness was 3.07 years (range $=0.03-23$ ). Among the homeless, lack of insurance was associated with uncontrolled blood pressure, whereas having diabetes, a mental illness, or multiple chronic diseases was associated with better blood pres- sure control. Table 2 displays the findings for study variables among the homeless patients with hypertension.

In the logistic regression analysis that included only homeless patients, when age, health insurance, mental health, diabetes, high cholesterol, alcohol abuse and mental illness were in the model, only mental illness, diabetes, and health insurance continued to be independently associated with better blood pressure control (Table 3).

We also performed a logistic regression analysis that included all patients (nonhomeless and homeless). When mental illness, health insurance, and housing status were in the model, mental illness (adjusted OR $=0.45 ; 95 \%$

Table 1. Study Variables Among Homeless and Nonhomeless Hypertensive Patients, New York City, 2014

\begin{tabular}{|c|c|c|c|}
\hline Variable & $\begin{array}{l}\text { Total Patients } \\
\quad \mathrm{N}=210\end{array}$ & $\begin{array}{l}\text { Homeless } \\
(n=177)\end{array}$ & $\begin{array}{l}\text { Nonhomeless } \\
\quad(n=33)\end{array}$ \\
\hline \multicolumn{4}{|l|}{ Sociodemographic characteristic } \\
\hline Age, mean (SD) [range], $\mathrm{y}^{\mathrm{a}}$ & 55.74 (10.99) [28-92] & $55.10(11.07)$ & $59.15(10.01)$ \\
\hline Systolic blood pressure, mean (SD) [range], mm Hg & $131.04(19.47)[86-210]$ & $131.76(20.05)$ & $127.18(15.70)$ \\
\hline Diastolic blood pressure, mean (SD) [range], $\mathrm{mm} \mathrm{Hg}$ & $79.76(12.34)[30-111]$ & $80.06(12.91)$ & $78.18(8.71)$ \\
\hline \multicolumn{4}{|l|}{ Blood pressure level $(n=210)$} \\
\hline Normal (<135/85 mm Hg), No. (\%) & $46(21.9)$ & $38(21.4)$ & $8(24.2)$ \\
\hline At risk $(\geq 135 / 85$ to $<140 / 90 \mathrm{~mm} \mathrm{Hg})$, No. $(\%)^{c}$ & $82(39)$ & $68(38.4)$ & $14(42.4)$ \\
\hline Stage 1, uncontrolled ( $\geq 140 / 90$ to $<160 / 100 \mathrm{~mm} \mathrm{Hg}$ ), No. (\%) & $53(25.2)$ & $43(24.2)$ & $10(30.3)$ \\
\hline Stage 2, very uncontrolled ( $\geq 160 / 100)$, No. (\%) & $29(13.8)$ & $28(15.8)$ & $1(0.03)$ \\
\hline Hypertension, uncontrolled ( $n=210)$, No. $(\%)$ & $82(39)$ & 71 & 11 \\
\hline Sex $(n=210)$, male, No. $(\%)$ & $158(75.2)$ & 136 & 22 \\
\hline \multicolumn{4}{|l|}{ Race $(n=206)$} \\
\hline White, No. (\%) & $32(15.5)$ & 26 & 6 \\
\hline African American, No. (\%) & $114(55.3)$ & 101 & 13 \\
\hline Hispanic, No. (\%) & $40(19.4)$ & 31 & 9 \\
\hline Asian, Native American, others, No. (\%) & $20(9.7)$ & 17 & 3 \\
\hline Health insurance $(n=209)$, No. $(\%)^{b}$ & $180(86.1)$ & 147 & 33 \\
\hline \multicolumn{4}{|l|}{ Insurance type $(n=176)$} \\
\hline Medicaid, No. (\%) & $118(67)$ & 100 & 18 \\
\hline Medicare, No. (\%) & $56(31.8)$ & 41 & 15 \\
\hline Other, No. (\%) & $2(1.1)$ & 2 & 0 \\
\hline \multicolumn{4}{|l|}{ Clinical indicator } \\
\hline Diabetes $(n=204)$, No. (\%) & $75(36.8)$ & 60 & 15 \\
\hline Coronary artery diseases $(n=204)$, No. $(\%)^{a}$ & $41(20.1)$ & 30 & 11 \\
\hline Kidney disease $(n=204)$, No. $(\%)$ & $8(3.9)$ & 5 & 3 \\
\hline Hypercholesterolemia $(n=204)$, No. $(\%)^{b}$ & $63(30.9)$ & 44 & 19 \\
\hline Number of chronic diseases $(n=176)$, mean (SD) [range ${ }^{b}$ & $1.91(0.97)[0-5]$ & $1.82(0.93)$ & $2.39(1.02)$ \\
\hline Mental illness $(n=201)$, No. (\%) & $127(63.2)$ & 104 & 23 \\
\hline Number of mental illness $(n=100)$, mean $(S D)$ [range] & $1.18(0.44)[0-3]$ & $1.16(0.44)$ & $1.26(0.45)$ \\
\hline Body mass index $(n=205)$, mean (SD) [range] & $30.55(6.97)[18.36-51.24]$ & $30.36(6.42)$ & $31.58(9.36)$ \\
\hline Obesity $(n=176)$, No. $(\%)$ & $95(46.6)$ & 79 & 16 \\
\hline Substance abuse $(n=160)$, No. (\%) & $30(18.8)$ & 25 & 5 \\
\hline Alcohol abuse $(n=164)$, No. $(\%)^{a}$ & $25(15.2)$ & 24 & 1 \\
\hline Smoking cigarettes $(n=181)$, No. $(\%)^{a}$ & $89(49.2)$ & 80 & 9 \\
\hline Number of current daily cigarettes ( $n=84)$, mean (SD) [range] & $9.08(5.71)[2-31]$ & $8.98(5.47)$ & $9.89(7.84)$ \\
\hline
\end{tabular}


$\mathrm{CI}, 0.25-0.82$ ) and health insurance (adjusted $\mathrm{OR}=1.22$; $95 \% \mathrm{CI}, 1.14-1.31$ ) were independently associated with better blood pressure control, and housing status was not (adjusted $\mathrm{OR}=1.07 ; \mathrm{CI}, 0.47-2.43$ ).

\section{DISCUSSION}

The $40.1 \%$ rate of uncontrolled blood pressure among the homeless, with $15.8 \%$ having stage 2 hypertension, is alarming. The rates of uncontrolled blood pressure among US hypertensive persons aged 40 to 59 years and 60 to 79 years who are under treatment are $19.6 \%$ and $24.8 \%$, respectively. ${ }^{21}$ Considering the remarkably higher prevalence of other important risk factors for cardiovascular events among homeless, ${ }^{6,8,11,12}$ effective treatment and better blood pressure control among hypertensive homeless patients becomes even more important. Lack of health insurance was a strong predictor of uncontrolled blood pressure among both homeless and nonhomeless hypertensive adults. We hypothesize that the lack of consistent medical insurance limits access to a steady supply of medications and likely contributes to missing follow-up visits with clinicians. Although we did not directly collect data on treatment adherence, we hypothesize that uncontrolled blood pressure is likely due to lower adherence to a medical regimen or a lack of access to healthy food choices and exercise during homelessness or in the shelters.

Contrary to our original hypothesis, having one or more mental illnesses was not associated with the increased risk of uncontrolled blood pressure. Mental illness can have a profound impact on access to

Table 2. Bivariate Analysis of Hypertension Among Homeless Hypertensive Patients, New York City, 2014

\begin{tabular}{|c|c|c|c|}
\hline Variable & $\begin{array}{c}\text { Total Patients } \\
\mathrm{n}=177\end{array}$ & $\begin{array}{c}\text { Controlled } \\
\text { Hypertension } \\
n=106(59.9 \%)\end{array}$ & $\begin{array}{c}\text { Uncontrolled } \\
\text { Hypertension } \\
\mathrm{n}=71(40.1 \%)\end{array}$ \\
\hline Age $(n=177)$, mean (SD) [range], y & 55.10 (11.07) [28-92] & $55.27(10.65)$ & $54.85(11.76)$ \\
\hline Duration of homelessness $(n=39)$, mean (SD) [range], $y$ & 3. $07(5.04)[0.03-23]$ & $3.08(4.24)$ & $3.07(5.97)$ \\
\hline Systolic blood pressure $(n=177)$, mean $(S D)[\text { range }]^{b}$ & $131.76(20.05)[86-210]$ & $118.85(10.99)$ & $151.03(14.17)$ \\
\hline Diastolic blood pressure $(n=177)$, mean $(S D)[\text { range }]^{b}$ & $80.06(12.91)[30-111]$ & $73.71(8.73)$ & $89.54(12.34)$ \\
\hline \multicolumn{4}{|l|}{ Blood pressure level $(n=177)$} \\
\hline Normal (<135/85 mm Hg), No. (\%) & $38(21.5)$ & $\ldots$ & $\ldots$ \\
\hline At risk $(\geq 135 / 85$ to $<140 / 90 \mathrm{~mm} \mathrm{Hg})$ & $68(38.4)$ & $\ldots$ & $\ldots$ \\
\hline Stage 1 , uncontrolled $(\geq 140 / 0$ to $<160 / 100 \mathrm{~mm} \mathrm{Hg}$ ) & $43(24.3)$ & $\ldots$ & $\ldots$ \\
\hline Stage 2 , very uncontrolled ( $\geq 160 / 100 \mathrm{~mm} \mathrm{Hg}$ ) & $28(15.8)$ & $\ldots$ & $\ldots$ \\
\hline Sex, male $(n=177)$ & $136(76.8)$ & 79 & 57 \\
\hline \multicolumn{4}{|l|}{ Race $(n=175)$} \\
\hline White, No. (\%) & $26(14.9)$ & 15 & 11 \\
\hline African American, No. (\%) & $101(57.7)$ & 58 & 43 \\
\hline Hispanic, No. (\%) & $31(17.7)$ & 19 & 12 \\
\hline Asian, Native American, others, No. (\%) & $17(9.7)$ & 13 & 4 \\
\hline Health insurance $(n=176)$, No. $(\%)^{a}$ & $147(83.5)$ & 93 & 54 \\
\hline \multicolumn{4}{|l|}{ Insurance type $(n=143)$} \\
\hline Medicaid, No. (\%) & $100(69.9)$ & 62 & 38 \\
\hline Medicare, No. (\%) & $41(28.7)$ & 29 & 12 \\
\hline Other, No. (\%) & $2(1.4)$ & 0 & 2 \\
\hline Diabetes $(n=171)$, No. $(\%)^{b}$ & $60(35.1)$ & 45 & 15 \\
\hline Coronary artery disease $(n=171)$, No. $(\%)$ & $30(17.5)$ & 19 & 11 \\
\hline Kidney disease $(n=171)$, No. (\%) & $5(2.9)$ & 3 & 2 \\
\hline Hypercholesterolemia ( $n=171)$, No. (\%) & $44(25.7)$ & 31 & 13 \\
\hline Mental illness $(n=168)$, No. $(\%)^{\mathrm{a}}$ & $104(61.9)$ & 70 & 34 \\
\hline Number of mental illness ( $n=100)$, mean (SD) [range] & $1.16(0.44)[0-3]$ & $1.17(0.45)$ & $1.15(0.43)$ \\
\hline Body mass index $(n=172)$, mean (SD) [range] & $30.36(6.42)$ [18-49] & $30.68(6.07)$ & $29.87(6.93)$ \\
\hline Obesity $(n=171)$, No. (\%) & $79(46.2)$ & 51 & 28 \\
\hline Substance abuse $(n=131)$, No. $(\%)$ & $25(19.1)$ & 15 & 10 \\
\hline Alcohol abuse $(n=133)$, No. $(\%)$ & $24(18)$ & 12 & 12 \\
\hline Smoking cigarettes $(n=150)$, No. $(\%)$ & $80(53.3)$ & 50 & 30 \\
\hline Number of current daily cigarettes $(n=76)$, mean (SD) [range] & $8.98(5.47)[2-31]$ & $8.99(5.92)$ & $8.96(4.67)$ \\
\hline
\end{tabular}




\section{Table 3. Logistic Regression Analysis of Independent Variables on Uncontrolled Hypertension Among Homeless Adults, New York City, 2014}

\begin{tabular}{|c|c|c|c|c|}
\hline \multirow[b]{2}{*}{ Variable } & \multicolumn{4}{|c|}{ Uncontrolled Hypertension } \\
\hline & $\begin{array}{c}\text { Unadjusted } \\
\text { OR }\end{array}$ & $95 \% \mathrm{Cl}$ & $\begin{array}{l}\text { Adjusted } \\
\text { OR }^{\mathrm{a}}\end{array}$ & $95 \% \mathrm{Cl}$ \\
\hline Age & $\ldots$ & $\ldots$ & 1.007 & $0.97-1.03$ \\
\hline Health insurance ${ }^{b}$ & 0.41 & $0.18-0.92$ & 0.39 & $0.16-0.97$ \\
\hline Diabetes & 0.35 & $0.17-0.70$ & 0.38 & $0.18-0.81$ \\
\hline Hypercholesterolemiab & 0.53 & $0.25-1.11$ & 0.52 & $0.23-1.19$ \\
\hline Mental illness ${ }^{b}$ & 0.45 & $0.24-0.86$ & 0.42 & $0.21-0.84$ \\
\hline \multicolumn{5}{|l|}{ OR $=$ odds ratio. } \\
\hline \multicolumn{5}{|c|}{$\begin{array}{l}\text { adjusted for age, health insurance, mental health, diabetes, high cholesterol, alcohol abuse, } \\
\text { and obesity. } \\
\text { b } P<.05 \text {. }\end{array}$} \\
\hline
\end{tabular}

care services via mobile communication devices), which have been used in the general population to improve the management of chronic diseases with reminders and health education for diet and exercise, may be effective and should be explored. ${ }^{27-33}$

Providing opportunities at shelters or shelter-based clinics where the homeless often seek care and where they have access to other social and system supports could address the multilevel barriers to hypertension control. These opportunities would adopt the elements of the chronic care model, which include targeted outreach to support health behavior change, collaborative goal setting, and reminders and feedback that empower patients.

health care and needs to be addressed systematically using team efforts that engage mental health and primary care clinicians, shelter staff and case workers, and social workers. We noted that most of our homeless patients with mental illness often resided in shelters that have nursing support and staff to provide reminders and help with adherence to mental health medications, which may have also helped to improve adherence to hypertension medications. Additionally, it is likely that having another chronic illness increased the number of clinical encounters and therefore improved detection and treatment of uncontrolled blood pressure among the homeless with mental illness.

An overwhelming majority of the homeless lose their housing secondary to eviction and inability to pay rent or domestic and family disputes, ${ }^{1}$ and mental illness is often a byproduct of homelessness rather than its primary cause. ${ }^{1,12}$ Addressing fundamental causes of homelessness may help address mental health issues. Considering inadequate access to proper mental health care for the general population in the United States, targeted programs aimed at highly vulnerable populations of the homeless who lack other social supports and social capital should be considered.

Homeless patients who are elligible for Medicaid state-supported health insurance may not necessarily have access to it because of the complicated process to obtain and maintain it. The Patient Protection and Affordable Care Act may result in more opportunities for the homeless to be insured. ${ }^{22}$ Prejudice against the homeless and minorities' health care needs and the health system's focus on addressing their acute care have been well documented. ${ }^{23-26}$ These issues need to be addressed, and communication with health care providers, improved. Considering the mobile nature of the homeless populations and their lack of consistent housing, mobile health strategies (the delivery of health
We could not find any association between years of homelessness and uncontrolled blood pressure, which we hypothesize is due to a limited number of reported years of homelessness. That neither obesity nor body mass index was associated with uncontrolled blood pressure is likely because the level of obesity in our total population is high. Substance or alcohol abuse were also not independently associated with uncontrolled

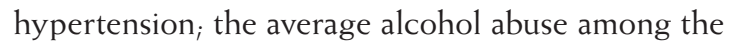
homeless is high, and the relationship with blood pressure is probably masked or cofounded by the significant association of mental illness with substance or alcohol abuse. We did not find any racial differences between controlled and uncontrolled hypertensive homeless patients, largely because of the overwhelming minority population of the homeless. Having diabetes was associated with better blood pressure control among homeless patients, possibly because they had more frequent clinic visits or they received more rigorous blood pressure control for their diabetes by their clinicians.

There are limitations to our study. Medical records review poses limitations to objective assessments of important components of predictors that may have not been documented, such as duration and severity of mental illness, substance or alcohol abuse, or other chronic diseases, as well as data on current length, episodes, or duration of lifetime homelessness. We were unable to collect specific data on hypertension awareness or medications adherence, and we used only a single blood pressure reading measured during the most recent visit. Blood pressures are, however, measured in a consistent way and according to national recommendations in all of our shelter-based clinics, which have regular quality assurance assessment of measurement reliability and consistency.

A more comprehensive examination of the behavioral and psychosocial factors associated with poor 
blood pressure control in future research may provide a better understanding of the pathway to uncontrolled hypertension in this high-risk population. Nevertheless, structural strategies to prevent and address homelessness are paramount and need to be implemented.

To read or post commentaries in response to this article, see it online at http://www.annfammed.org/content/14/1/41.

Key words: hypertension; homeless persons; healthcare disparities; blood pressure

Submitted May 31, 2015; submitted, revised, September 14, 2015; accepted November 3, 2015.

Acknowledgment: The leadership and staff at the NYU Lutheran's Community Medicine Program provided invaluable support to this project.

\section{References}

1. National Alliance to End Homelessness, Homelessness Research Institute. The State of Homelessness in America 2013. http://b.3cdn. net/naeh/bb34a7e4cd84ee985c_3vm6r7cjh.pdf. Published Apr 2013. Accessed Jul 22, 2014.

2. Fargo J, Metraux S, Byrne T, et al. Prevalence and risk of homelessness among US veterans. Prev Chronic Dis. 2012;9:E45.

3. Culhane DP, Metraux S, Byrne T, Stino M, Bainbridge J. The age structure of contemporary homelessness: evidence and implications for public policy. Anal Soc Issues Public Policy. 2013;13(1):228-244.

4. Kushel MB, Vittinghoff $E_{1}$ Haas JS. Factors associated with the health care utilization of homeless persons. JAMA. 2001;285(2):200-206.

5. Gelberg L1, Linn LS. Assessing the physical health of homeless adults. JAMA. 1989;262(14):1973-1979.

6. Szerlip MI, Szerlip HM. Identification of cardiovascular risk factors in homeless adults. Am J Med Sci. 2002;324(5):243-246.

7. Moczygemba LR, Kennedy AK, Marks SA, Goode JV, Matzke GR. A qualitative analysis of perceptions and barriers to therapeutic lifestyle changes among homeless hypertensive patients. Res Social Adm Pharm. 2013;9(4):467-481.

8. Kim DH, Daskalakis C, Plumb JD, et al. Modifiable cardiovascular risk factors among individuals in low socioeconomic communities and homeless shelters. Fam Community Health. 2008;31(4):269-280.

9. Savage CL, Lindsell CJ, Gillespie GL, Dempsey A, Lee RJ, Corbin A. Health care needs of homeless adults at a nurse-managed clinic. J Community Health Nurs. 2006;23(4):225-234.

10. Kleinman LC, Freeman H, Perlman J, Gelberg L. Homing in on the homeless: assessing the physical health of homeless adults in Los Angeles County using an original method to obtain physical examination data in a survey. Health Serv Res. 1996;31(5):533-549.

11. Lee TC, Hanlon JG, Ben-David J, et al. Risk factors for cardiovascular disease in homeless adults. Circulation. 2005;111(20):2629-2635.

12. Asgary R, Garland V, Jakubowski A, Sckell B. Colorectal cancer screening among the homeless population of New York City shelterbased clinics. Am J Public Health. 2014;104(7):1307-1313.

13. Khandor E, Mason K, Chambers C, Rossiter K, Cowan L, Hwang $S W$. Access to primary health care among homeless adults in Toronto, Canada: results from the Street Health survey. Open Med. 2011;5(2):e94-e103.

14. Appel LJ, Brands MW, Daniels SR, Karanja N, Elmer PJ, Sacks FM; American Heart Association. Dietary approaches to prevent and treat hypertension: a scientific statement from the American Heart Association. Hypertension. 2006;47(2):296-308.

15. Appel LJ, Champagne CM, Harsha DW, et al.; Writing Group of the PREMIER Collaborative Research Group. Effects of comprehensive lifestyle modification on control: main results of the PREMIER clinical trial. JAMA. 2003;289(16):2083-2093.
16. Stamler R, Stamler J, Grimm R, et al. Nutritional therapy for high . Final report of a four-year randomized controlled trial-the Hypertension Control Program. JAMA. 1987;257(11):1484-1491.

17. Taylor EF, Lake T, Nysenbaum J, Peterson G, Meyers D. Coordinating Care in the Medical Neighborhood: Critical Components and Available Mechanisms. http://pcmh.ahrq.gov/sites/default/files/ attachments/Coordinating\%20Care\%20in\%20the\%20Medical\%20 Neighborhood.pdf. Published Jun 2011. Accessed Feb 2015.

18. Pham HH. Good neighbors: how will the patient-centered medical home relate to the rest of the health-care delivery system? J Gen Intern Med. 2010;25(6):630-634.

19. US Department of Health and Human Services. The Seventh Report of the Joint National Committee on Prevention, Detection, Evaluation, and Treatment of High (2004). http://www.nhlbi.nih.gov/files/docs/ guidelines/jnc7full.pdf. Published Aug 2004. Accessed Dec 2014.

20. Krejcie, R.V. \& Morgan, D.W. Determining sample size for research activities. Educ Psychol Meas. 1970;30(iss):607-610.

21. Joffres M, Falaschetti E, Gillespie C, Robitallie C, Loustalot F, Poulter $\mathrm{N}$, et al. Hypertension prevalence, awareness, treatment and control in national surveys from England, the USA and Canada, and correlation with stroke and ischemic heart disease mortality: a cross-sectional study. BMJ Open. 2013;3(8):e003423.

22. Department of Health and Human Services. Affordable Care Act: Title IV; sections 4302 and 4106. http://www.hhs.gov/healthcare/ rights/law/. Accessed Jul 22, 2014.

23. Wen CK, Hudak PL, Hwang SW. Homeless people's perceptions of welcomeness and unwelcomeness in healthcare encounters. J Gen Intern Med. 2007;22(7):1011-1017.

24. Cooper LA, Roter DL, Carson KA, et al. The associations of clinicians' implicit attitudes about race with medical visit communication and patient ratings of interpersonal care. Am J Public Health. 2012;102(5):979-987.

25. Hausmann LR, Hannon MJ, Kresevic DM, Hanusa BH, Kwoh CK, Ibrahim SA. Impact of perceived discrimination in healthcare on patient-provider communication. Med Care. 2011;49(7):626-633.

26. Teal $C R$, Shada RE, Gill AC, et al. When best intentions aren't enough: helping medical students develop strategies for managing bias about patients. J Gen Intern Med. 2010;25(2)(Suppl 2):S115-S118.

27. Eyrich-Garg KM. Mobile phone technology: a new paradigm for the prevention, treatment, and research of the non-sheltered "street" homeless? J Urban Health. 2010;87(3):365-380.

28. Post LA, Vaca FE, Doran KM, Luco C, Naftilan M, Dziura J, et al. New media use by patients who are homeless: the potential of mHealth to build connectivity. J Med Internet Res. 2013;15(9):e195.

29. Márquez Contreras E, de la Figuera von Wichmann M, Gil Guillén $V$, et al. [Effectiveness of an intervention to provide information to patients with hypertension as short text messages and reminders sent to their mobile phone (HTA-Alert)]. Aten Primaria. 2004;34(8):399-405.

30. McGillicuddy JW, Gregoski MJ, Weiland AK, Rock RA, BrunnerJackson BM, Patel SK, et al. Mobile health medication adherence and control in renal transplant recipients: a proof-of-concept randomized controlled trial. JMIR Res Protoc. 2013;2(2):e32.

31. Dick JJ, Nundy S, Solomon MC, Bishop KN, Chin MH, Peek ME. Feasibility and usability of a text message-based program for diabetes self-management in an urban African-American population. J Diabetes Sci Technol. 2011;5(5):1246-54.

32. Guy R, Hocking J, Wand H, Stott S, Ali H, Kaldor J. How effective are short message service reminders at increasing clinic attendance? A meta-analysis and systematic review. Health Serv Res. 2012;47(2):614-632.

33. Asgary R, Sckell B, Alcabes A, Naderi R, Adongo P, Ogedegbe G. Perceptions, attitudes, and experience regarding mHealth among homeless persons in New York City Shelters. J Health Commun. 2015;20(12)1473-1480. 